\title{
O discurso da responsabilidade social e da sustentabilidade na comunicação organizacional da Vale
}

The discourse on social responsibility and on sustainability in Vale's organizational communication

El discurso de la responsabilidad social y de la sustentabilidad en la comunicación organizacional de la Vale

\section{Gisele Dotto Reginato}

- Doutoranda no Programa de Pós-Graduação em Comunicação e Informação da Universidade Federal do Rio Grande do Sul (UFRGS)

- Bolsista Capes e membro do Núcleo de Pesquisa em Jornalismo - UFRGS/CNPq

- Mestre em Comunicação e graduada em Jornalismo pela Universidade Federal de Santa Maria (UFSM)

- Foi professora substituta do Curso de Jornalismo da UFSM.

- Pesquisa linguagem e produção de sentidos, especialmente no que tange às teorias do jornalismo, da notícia e do discurso

- E-mail: giselereginato@gmail.com

\section{Débora Flores Dalla Pozza}

- Graduada em Comunicação Social - Jornalismo pela Universidade Federal de Santa Maria (UFSM)

- Membro do grupo de pesquisa "A dinâmica das interações entre produção e recepção nos jornais do Rio Grande do Sul” - Fapergs/PQG 2011

- Pesquisa os elementos do discurso jornalístico aplicados à assessoria de imprensa

- E-mail: debora.dpozza@gmail.com 


\title{
Resumo
}

Este artigo analisa os efeitos de sentido de responsabilidade social e sustentabilidade nos releases institucionais da empresa Vale. Trabalhando com os preceitos teórico-metodológicos da análise de discurso de linha francesa, ele problematiza as memórias discursivas dos conceitos de responsabilidade social e sustentabilidade. A partir da análise, entendemos que tais temáticas são incorporadas à cultura organizacional por serem um diferencial competitivo no mercado, mas, apesar do caráter informativo, os textos não apresentam as contradições e os tensionamentos envolvidos na temática.

PALAVRAS-CHAVE: COMUNICAÇÃO ORGANIZACIONAL • RESPONSABILIDADE SOCIAL • SUSTENTABILIDADE • DISCURSO • VALE

\begin{abstract}
This article analyzes the effects of feelings of social responsibility and sustainability in the press releases of the corporation. Based on the theoretical and methodological precepts of discourse analysis of the French school, we examine the discursive memories of social responsibility and sustainability concepts. We understand that these issues are incorporated with the organizational culture as they are a competitive differential in the market, but, despite being of an informative nature, the texts do not present the contradictions and the tensions involved in the thematic.
\end{abstract}

\section{KEYWORDS: ORGANIZATIONAL COMMUNICATION - SOCIAL RESPONSIBILITY • SUSTAINABILITY • DISCOURSE • VALE}

\section{Resumen}

Este artículo analiza los efectos de sentido de responsabilidad social y sustentabilidad en los comunicados de prensa de la empresa Vale. Trabajando con los supuestos teórico-metodológicos del análisis del discurso de línea francesa, el texto problematiza las memorias discursivas de los conceptos de responsabilidad social y sustentabilidad. A partir del análisis, entendemos que esas temáticas son incorporadas a la cultura organizacional porque son un diferencial competitivo en el mercado, pero, a pesar del carácter informativo, los textos no presentan las tensiones involucradas en la temática.

PALABRAS CLAVES: COMUNICACIÓN ORGANIZACIONAL • RESPONSABILIDAD SOCIAL・ SUSTENTABILIDAD • DISCURSO • VALE 
A partir dos anos 1990, os ideais políticos e econômicos do neoliberalismo foram aderidos por grande parte da política internacional, o que presumiu a expansão da ideia de separação entre Estado e economia. Santa Cruz (2006, p. 66) sustenta que, com o advento desse novo sistema, passou-se a defender internacionalmente um Estado que zelasse por interesses privados ao reduzir sua intervenção ao mínimo necessário: "Esse mínimo se constitui na produção de bens considerados absolutamente públicos (como segurança e justiça) e a garantia institucional da manutenção das regras que viabilizam o jogo capitalista".

Ao passo que o estado reduziu sua intervenção no campo econômico, novas temáticas passaram ao centro das discussões sociais na era neoliberal, como a função das empresas na sociedade e o papel socioambiental que cabe a elas (Santa Cruz, 2006), bem como a seus proprietários, empregados e acionistas. Nesse contexto, os termos responsabilidade social e sustentabilidade têm adquirido crescente relevância nos cenários administrativo, político e até mesmo midiático, consistindo atualmente em um diferencial competitivo para empresas de distintos setores por trazerem resultados significativos a sua imagem no mercado.

Dessa forma, compreender os sentidos materializados no discurso da responsabilidade social e da sustentabilidade articulado por empresas, refletindo teoricamente sobre o assunto, se faz necessário diante da relevância que a temática assume atualmente na produção de conteúdo comunicacional das organizações. Por isso, a proposta deste artigo é analisar o discurso da empresa Vale, a fim de verificar quais efeitos de sentidos são produzidos quando a organização retrata iniciativas empresariais de responsabilidade social e sustentabilidade.

Graças à ampla produção de conteúdos relacionados aos valores da responsabilidade social e da sustentabilidade observada na página web da "Sala de imprensa" da Vale ${ }^{1}$, é possível visualizar a imagem de si que ela elabora no discurso institucional. As notícias que se referem diretamente aos ditos valores são enquadradas na página em categorias denominadas "Investimento social" e "Meio ambiente". Em acesso à "Sala de imprensa" em 24 de agosto de 2012, dentre as vinte notícias expostas na primeira página, detectamos sete enquadradas nas categorias citadas. Na mesma página, ainda constavam duas notícias classificadas na categoria "Cultura", correlacionada à temática da responsabilidade social.

A escolha por contemplar a Vale na análise também se justifica por ela ter sido apontada como a quarta empresa mais citada pelos consumidores como socialmente responsável, de acordo com o estudo Monitor de Responsabilidade Social Corporativa 2010, realizado pelo instituto de pesquisa de mercado e opinião Market Analysis².

\footnotetext{
${ }^{1}$ Disponível em: <http://saladeimprensa.vale.com/pt/release/index.asp>. Acesso em: 24/08/2012

${ }^{2}$ Ranking do estudo disponível em: http://www.empresaresponsavel.com/links/ ranking_respsocial_2010.pdf. Acesso em: $13 / 11 / 2011$.
} 
Ao analisarmos os releases institucionais da Vale que retratam iniciativas das áreas de responsabilidade social e sustentabilidade da instituição, devemos levar em conta os discursos anteriores sobre responsabilidade social, sustentabilidade e comunicação organizacional relacionados a esses valores para compreender os sentidos materializados na produção de conteúdo da Vale. Assim, é preciso buscar outras memórias discursivas sobre o conceito para que a análise discursiva considere o contexto que perpassa o release institucional analisado, uma vez que

o texto é a parte visível ou material de um processo altamente complexo que inicia em outro lugar: na sociedade, na cultura, na ideologia, no imaginário. (...) Importa compreender que existe uma exterioridade que não apenas repercute no texto, mas que de fato o constitui e não pode ser dele apartada (Benetti, 2008, p. 111 - grifos da autora).

Dessa forma, antes de partirmos para a análise dos efeitos de sentidos materializados nos releases, percorreremos um trajeto de levantamento de memórias discursivas sobre a responsabilidade social, a sustentabilidade, a empresa Vale - especialmente no que tange às iniciativas relacionadas à responsabilidade social e à sustentabilidade -, bem como sobre a abordagem desses valores empresariais pela comunicação organizacional.

\section{MEMÓRIAS DISCURSIVAS: A RESPONSABILIDADE SOCIAL E A SUSTENTABILIDADE}

Para melhor compreensão dos sentidos que se materializam no termo responsabilidade social, é interessante perceber que o debate sobre o conceito é tão antigo quanto as próprias concepções de empresas e negócios. Borger (2001) explica que, em seus primórdios, a própria instalação da empresa já era vista como responsabilidade social, uma vez que gerava empregos, renda à população e investimentos e benefícios à cidade onde se instalava. Entretanto, essas funções passaram a ser vistas como obrigação mínima das empresas com o decorrer do tempo, e a evolução na organização de órgãos trabalhistas e sindicais reconfiguraram as condições de trabalho nas mesmas. Além disso, os avanços tecnológicos trouxeram consequências às produções industriais, como o aumento dos recursos utilizados, a modernização de máquinas e ferramentas.

Com isso, outros aspectos relativos à influência das empresas no ambiente foram questionados, trazendo ao centro dos debates o impacto das indústrias sobre o meio ambiente em que se encontram, os benefícios trabalhistas concedidos pelas empresas, o apoio a projetos locais que desenvolvam educação, saúde, cultura ou outro aspecto de interesse social. Assim, o debate "não passou mais a girar em torno da necessidade e/ou conveniência das ações que implicam responsabilidade social. Essa passou a ser ponto pacífico" (Borger, 2001, p. 9).

Conceituar e delimitar a responsabilidade social é um desafio, uma vez que suas práticas são diversas e que sua concepção teórica vem recebendo diversas interpretações historicamente, empregadas de acordo com o contexto, com quem a emprega e para quem ela se dirige, se- 
gundo Lucia Santa Cruz (2006). A autora entende que o termo responsabilidade social e seus sinônimos se referem, em geral, a um conjunto de ações relativas à sociedade realizadas por empresas e que vão além da esfera direta e imediata de sua atividade econômica. Além disso, propõe que a responsabilidade social e seus sinônimos funcionam como um discurso que indica a rearticulação do papel das empresas na sociedade. Os processos comunicacionais são premissa para esse discurso ser tecido, configurando-se como lugar de interconexão entre o público (social) e o privado (organizações particulares).

Na construção de um discurso socialmente responsável, a sustentabilidade ${ }^{3}$ tem assumido um foco central. É relevante dar atenção a esse discurso, já que o setor empresarial ${ }^{4}$ se apropria de parte do ideário ecológico e, segundo Fátima Portilho (2010), se autointitula como o principal segmento capaz de levar adiante o projeto de uma sociedade ambientalmente sustentável. E, apesar de o termo sustentabilidade ser constantemente vinculado no imaginário social a uma forma "verde" de ser e estar no mundo, ele não se reduz à questão ambiental, uma vez que mescla três elementos que precisam estar em harmonia (Santos, 2005): o desenvolvimento econômico, a preservação dos ecossistemas e o desenvolvimento social.

Nesse sentido, é fundamental ressaltar que as noções de responsabilidade social e sustentabilidade partilham de interesses comuns e possuem uma intersecção de valores no que tange à preocupação social. Esses valores são resgatados pelas empresas quando os associam a suas imagens, pois são considerados relevantes no processo decisório de compra, ainda que, segundo Souza (2010), os consumidores não tenham uma visão clara a respeito do que significa exatamente "ser sustentável" e socialmente responsável. De qualquer forma, para o autor, esse processo de aumento da importância do tema na percepção dos consumidores só tenderá a crescer, impactando decisões sobre produtos, marcas, formatos de lojas, canais de vendas e comunicação.

\section{A VALE E A RESPONSABILIDADE SOCIOAMBIENTAL EM SEU PERCURSO}

Criada por decreto-lei como empresa estatal, em junho de 1942, sob a denominação Companhia Vale do Rio Doce, a Vale é uma organização global de mineração que também atua nas áreas de logística, fertilizantes, energia e carvão. Privatizada em maio de 1997, possui atualmente escritórios e operações em 39 países e é líder mundial na produção de minério de ferro e pelotas e segunda maior produtora de níquel. Sua sede encontra-se no Brasil e, conforme consta no relatório institucional "Vale no mundo" (Vale, 2011), ela emprega diretamente mais de 119 mil pessoas e outras 54 mil em projetos.

\footnotetext{
${ }^{3}$ Fritjof Capra (2002) diz que o conceito de sustentabilidade foi criado no começo da década de 1980 por Lester Brown, fundador do Instituto Worldwatch, que definiu a sociedade sustentável como aquela que é capaz de satisfazer suas necessidades sem comprometer as chances de sobrevivência das gerações futuras.

${ }^{4}$ Portilho (2010) afirma que o setor empresarial aparece no cenário ambientalista somente a partir da década de 1980, quando começa a abandonar sua imagem de "vilão da ecologia" e a adotar a imagem de "amigo do verde".
} 
No "Relatório de sustentabilidade - 2010", a organização apresenta-se da seguinte forma:

A Vale é uma empresa global de mineração que preza a ética nos negócios, a responsabilidade econômica, social e ambiental, e, acima de tudo, as pessoas. Sua meta é contribuir para a construção de um legado positivo para as gerações futuras nas regiões onde atua (Vale, 2010).

É notória a preocupação da empresa em ressaltar, na imagem de si que constrói no discurso institucional, sua responsabilidade socioambiental e enfatizar o valor empresarial da sustentabilidade. No relatório "Vale no mundo", a instituição expõe que "responsabilidade socioambiental é um compromisso estratégico".

A Vale sustenta em seu discurso institucional que demonstra compromisso com a responsabilidade social em todo o mundo com as seguintes práticas: criação de empregos e crescimento econômico; programas educacionais e culturais; e atividades de investimento social (por meio da Fundação Vale). A Fundação Vale, reiterando em seu discurso o desenvolvimento de iniciativas em comunidades onde se localizam as operações da empresa, tem como intuito contribuir para o desenvolvimento integrado econômico, ambiental e social desses locais. No relatório "Vale no mundo", a organização ainda salienta a preocupação com a preservação ambiental: no Espírito Santo, mantém a Reserva Natural Vale, uma área de cerca de 218 km², onde são protegidas 2.389 espécies de fauna e 2.625 de flora. Também em Carajás (PA), a empresa ajuda a proteger cerca de $8.000 \mathrm{~km}^{2}$ de florestas nativas.

Tais iniciativas empresariais relacionadas à responsabilidade social e à sustentabilidade estão envoltas em uma mentalidade corporativa que as situa como estratégia de mercado, uma vez que os valores de responsabilidade social e sustentabilidade já são considerados relevantes no processo decisório de compra. Pesquisa feita na Bélgica, Dinamarca, França, Alemanha, Grã Bretanha, Itália, Holanda, Portugal, Espanha, Suécia e Suíça aponta que 70\% dos consumidores consideram o compromisso de uma empresa com a responsabilidade social como um aspecto importante quando compram produtos ou serviços e que $40 \%$ estariam dispostos a pagar mais por eles (Masera, 2001).

Por tal motivo, "grandes corporações, como Petrobras, Vale, Banco Itaú, Bradesco e Santander, disputam a liderança no posicionamento e buscam comunicar de forma consistente seu alinhamento 'verde' e sustentável" (Souza, 2010, p. 10 - grifo do autor). Assim, tornou-se praticamente uma exigência mercadológica que os valores da responsabilidade social e da sustentabilidade sejam incorporados pela cultura da organização e comunicados eficientemente a seus públicos. 


\section{RESPONSABILIDADE SOCIAL E SUSTENTABILIDADE NA COMUNICAÇÃO ORGANIZACIONAL}

Na prática gerencial, os conceitos de responsabilidade social e sustentabilidade devem ser vistos não como ações isoladas da empresa, mas como valores que contemplam aspectos que vão além da relação comercial da organização e que devem ser internalizados por cada pessoa que se relaciona com ela. De acordo com Wilson Bueno (2006, p. 3), a responsabilidade socioambiental "não se viabiliza, portanto, a partir de uma decisão ou vontade do topo da organização, mas deve permear todos os seus públicos e parceiros (fornecedores, por exemplo), sendo expressão, pois, da própria cultura da organização".

A comunicação é o instrumento comumente utilizado com o intuito de disseminar a ética como um valor incorporado por todos na empresa, estimulando a cultura socialmente responsável. Por isso, é necessário o alinhamento entre identidade e imagem empresarial. A identidade, formada por valores, princípios, conceitos e sistemas, consiste em uma espécie de personalidade da empresa; a imagem é o que a empresa deseja projetar, o reflexo de sua identidade (Formentini, 2005). O grau de clareza da identidade empresarial afeta diretamente a coerência entre identidade e imagem. Essa, por sua vez, é construída por necessidade de legitimação da instituição em relação ao seu ambiente técnico-institucional.

Para Fábio B. Neves (2008, p. 7), a "imagem forma-se na mente do consumidor com base em atributos desejáveis ou rejeitáveis, pautados em valores considerados caros às comunidades onde as empresas atuam". Tendo por base essa afirmação, é possível entendermos por que, contemporaneamente, muitas empresas se apresentam como portadoras de consciência social e ambiental e constroem suas identidades em torno dessa posição. Isso porque o discurso socioambiental está tão consolidado atualmente que, quando uma pessoa ou uma empresa enuncia que não se pode maltratar o meio ambiente e que temos que ser responsáveis com o futuro do planeta, ela está, na posição de cidadão consciente, falando exatamente como outros cidadãos conscientes falariam. A partir do que diz Orlandi (2007), podemos entender que quem está falando não é essa pessoa, mas sim a posição dela, que lhe dá identidade.

Assim, de uma empresa que se anuncia como tendo responsabilidade social, não se espera que declare incentivo ao consumismo ou à degradação ambiental. Em função da representação que se tem de uma empresa engajada socialmente, espera-se que ela demonstre preocupação com questões sociais e ecológicas (REGINATO, 2011, p. 105-106).

No intuito de construir e disseminar a imagem empresarial e divulgar práticas e informações relacionadas à corporação, a comunicação organizacional utiliza ferramentas para produzir conteúdo aos seus públicos e buscar interação com os mesmos. Na contemporaneidade, as organizações estão envoltas por redes de relacionamento constituídas por grupos sociais e pessoas que vão consolidar seus negócios. De acordo com Ivone de Lourdes Oliveira (2003, p. 2), "esse 
aspecto relacional da organização é que possibilita a construção de sentido e que a transforma também em produtora de sentidos".

Além disso, a comunicação organizacional tem nas estratégias de inserção no campo midiático um de seus vetores principais: a representação na esfera midiática é uma forma de a organização se constituir em "modelo de identificação, atuando como força que atrai os públicos em torno de si, para o consumo de seus bens e serviços ou para o alinhamento com suas causas/ideias" (Sartor, 2011, p. 55). Por isso, a produção de conteúdos midiáticos possui um papel definitivo na comunicação organizacional no sentido de buscar visibilidade às instituições e às iniciativas por ela empreendidas ou apoiadas.

\section{OS EFEITOS DE SENTIDO MATERIALIZADOS: ALGUNS APONTAMENTOS}

Com base no estudo de outras memórias discursivas referentes ao contexto da responsabilidade social e da sustentabilidade, especialmente no que se relaciona à comunicação organizacional, reiteramos que os sentidos que perpassam o discurso da organização constroem a legitimidade das iniciativas de responsabilidade social e de sustentabilidade. Então, para que se busque materializar esses sentidos, apresentamos uma análise discursiva de quatro releases da Vale selecionados ao longo de uma semana na "sala de imprensa" da empresa", de forma que dois releases são classificados na página na categoria "Investimento social" e outros dois na categoria "Meio ambiente",

Os objetos selecionados para a análise foram: da categoria "Investimento social", os releases intitulados "Vale apoia registros de crianças em Cateme, Moçambique" ${ }^{6}$, de 07 de agosto de 2012, e "Biopalma recebe primeira safra de dendê de agricultores do programa de agricultura familiar", de 09 de agosto de 2012; da categoria "Meio ambiente", as matérias "Dia da saúde é celebrado no Parque Botânico Vale de São Luís"8, de 03 de agosto de 2012, e "Preservação: parceria entre Vale e órgãos ambientais salva animais silvestres" ${ }^{\prime 9}$, de 07 de agosto de 2012.

Entendemos que analisar o discurso presume compreender o que é dito, como é dito e quais os mecanismos dos processos de significação, ou seja, quais efeitos de sentido surgem na relação entre texto e contexto. Assim, trabalhamos com os preceitos teóricos da análise do discurso de linha francesa na tentativa de definir os efeitos de sentidos produzidos. A análise é feita tendo em conta as formações imaginárias (lugares de fala no discurso), constituídas como projeção

\footnotetext{
${ }^{5}$ Tal seleção do corpus de análise deste artigo foi recortada a partir de observação da "Sala de imprensa" da empresa durante todo o mês de agosto de 2012.

${ }^{6}$ Página disponível em: http://saladeimprensa.vale.com/pt/release/interna.asp?id=21793. Acesso em 24/08/2012.

${ }^{7}$ Página disponível em: http://saladeimprensa.vale.com/pt/release/interna.asp?id=21796. Acesso em 24/08/2012.

${ }^{8}$ Página disponível em: http://saladeimprensa.vale.com/pt/release/interna.asp?id=21785. Acesso em 24/08/2012.

${ }_{9}$ Página disponível em: http://saladeimprensa.vale.com/pt/release/interna. asp?id=21791. Acesso em 24/08/2012.
} 
das situações empíricas do ato discursivo (Orlandi, 1996). As relações imaginárias podem ser consideradas a maneira pela qual a posição dos participantes do discurso intervém nas condições de produção desse discurso. Portanto, o texto é dialógico porque comporta, no mínimo, o lugar de quem fala e o de quem interpreta, sendo que a relação do sujeito com o sentido depende de tais lugares de fala.

Existe nos processos discursivos uma série de formações imaginárias que designam o lugar que cada sujeito discursivo atribui a si e ao outro, a imagem que eles se fazem de seu próprio lugar e do lugar do outro. Nos mecanismos de toda formação social, há regras de projeção responsáveis por estabelecer as relações entre as situações discursivas e as posições dos diferentes participantes e as formações imaginárias podem ser designadas da seguinte forma, segundo Michel Pêcheux (1993, p. 83):

\footnotetext{
IA(A): Imagem do lugar de A para o sujeito colocado em A - "Quem sou eu para Ihe falar assim?"

IA(B): Imagem do lugar de B para o sujeito colocado em A - "Quem é ele para que eu the fale assim?"

IB(B): Imagem do lugar de B para o sujeito colocado em B - "Quem sou eu para que ele me fale assim?"

IB(A): Imagem do lugar de A para o sujeito colocado em B - "Quem é ele para que me fale assim?"
}

Tendo por base esses pressupostos teóricos da análise do discurso de linha francesa, começamos por analisar que os releases selecionados materializam sentidos sobre um lugar de fala institucional, mas não é em todos que a presença institucional da Vale é a mais relevante na notícia. É o caso de três das quatro matérias analisadas, como em "Biopalma recebe primeira safra de dendê de agricultores do programa de agricultura familiar", por exemplo, em que a presença institucional mais acentuada é a da usina extratora de óleo de palma, chamada Biopalma da Amazônia S.A., uma "empresa da Vale em sociedade com o Grupo MSP", conforme mostra o release em questão. Assim, a Vale distribui os créditos das iniciativas socioambientais retratadas às instituições mantidas pela empresa e que são diretamente responsáveis por tais ações. Entretanto, sempre há um espaço em todos os releases destinado à explicação das iniciativas, em que se esclarece qual o envolvimento da Vale com as mesmas e se reforça para o leitor uma poderosa voz institucional, a partir dos sistemas de representação de si (Benetti; Hagen, 2009).

Também há espaço no discurso dos releases para a presença institucional de outras organizações que contribuíram para a realização das iniciativas retratadas, como na matéria "Preservação: parceria entre Vale e órgãos ambientais salva animais silvestres", em que se salienta a parceria do Instituto Brasileiro do Meio Ambiente e dos Recursos Naturais Renováveis (Ibama) e do Instituto Chico Mendes de Conservação da Biodiversidade (ICMBio) com o Parque Zoobotânico Vale (PZV), localizado em Parauapebas (PA) e administrado pela Vale. 
O leitor - que está presente, como horizonte de antecipações, já no processo de produção do discurso (Storch, 2012, p. 62) - é construído de forma genérica, como se fosse a opinião pública de forma geral, a qual necessita tomar conhecimento das iniciativas da empresa em parceria com outras instituições para reconhecer sua contribuição social.

Outro ponto que devemos ressaltar é que três dos quatro releases analisados possuem uma ou mais falas de fontes consideradas "autoridades" nas ações retratadas das matérias. Assim, verificamos a preocupação de salientar a credibilidade das iniciativas no discurso por meio do uso de fontes oficiais, como é o caso em "Vale apoia registros de crianças em Cateme, Moçambique", em que tanto uma autoridade da Vale nesse país como uma representante do governo têm suas falas destacadas em duas citações diretas na notícia.

De modo geral, o material textual dos releases é organizado de acordo com o modelo: 1) acontecimento; 2) explicação do acontecimento; 3) detalhes extras sobre o acontecimento (inclui fala de autoridades em três das quatro matérias); 4) contextualização sobre o envolvimento da Vale com a iniciativa.

Assim, o discurso constitui-se em fonte de conhecimento não apenas sobre o acontecimento retratado em si, mas também sobre a iniciativa de responsabilidade social ou de sustentabilidade e, de forma mais rasa, sobre a problemática socioambiental que ela busca desenvolver. Além disso, como já dito, sempre há um espaço de esclarecimento sobre a relação que a Vale possui com a ação em destaque na notícia.

Quanto ao tema dos releases, o discurso foca no aspecto dos acontecimentos em si, bem como nos processos de construção e viabilização dos mesmos. Com base na organização do material textual e na forma como a temática é abordada, nota-se que o discurso é basicamente informativo e não apela para a propaganda explícita. Entretanto, não se materializam sentidos sobre a questão da estrutura social e/ou ambiental que envolve o acontecimento ou da historicidade das problemáticas socioambientais, o que relega a complexidade da realidade social do discurso.

Assim, não se desenvolve nas matérias uma problematização acerca da estrutura social que envolve as ações de responsabilidade socioambiental, o que deixa brechas no discurso para a interpretação da complexidade social relativa ao assunto. Nessa direção, o discurso parece servir principalmente como fonte de conhecimento das iniciativas retratadas em particular e do papel das instituições envolvidas para a realização de tal ação, sem prover informações relativas à situação da realidade socioambiental em que as instituições se inserem.

Verifica-se, assim, que a produção de conteúdo comunicacional da organização segue um padrão similar ao da produção jornalística na contemporaneidade: o texto articula-se em torno do factual, mas não investe na problematização da temática. Adelmo Genro Filho (1987, p. 187), em 
sua reflexão acerca das distintas abordagens teóricas já empreendidas sobre o jornalismo, destaca o reconhecimento teórico sobre a redução do jornalismo à função de informar acontecimentos:

a crítica de que o jornalismo, ao separar as notícias e tratá-las de forma descontínua, desintegra e atomiza o real favorecendo a superficialidade da reflexão e a alienação tornou-se um lugar comum que recebe, em cada autor, um verniz teórico diferente.

\section{CONSIDERAÇÕES FINAIS}

A responsabilidade social está sendo incorporada à cultura organizacional de muitas empresas, uma vez que passou a ser considerada um diferencial competitivo no mercado. Com isso, a busca por divulgação e comunicação desse valor pelas organizações que o cultivam é crescente.

A produção de conteúdo da comunicação organizacional, enquanto uma das principais ferramentas de posicionamento externo de instituições, busca legitimar iniciativas sociais por meio de seu discurso. Consideramos, pois, que o discurso da comunicação organizacional da empresa Vale aqui materializou sentidos sobre sua presença institucional, mas também ressaltou a figura de instituições que são mantidas por ela e articulam ações de responsabilidade social e sustentabilidade de forma autônoma.

Também se pode notar que o discurso analisado foi perpassado por elementos pertencentes ao padrão textual jornalístico, provavelmente devido a uma busca por conferir credibilidade às matérias. Exemplos desses elementos são: o viés informativo do texto, o emprego de falas de fontes para conferir efeitos de realidade, a busca por um tom objetivo na linguagem, articulação do texto em torno do factual e estruturação que parte da informação tida como mais importante para posterior detalhamento do acontecimento reportado. Essas marcas discursivas reconhecidas na análise conferem tom de veracidade ao acontecimento e contribuem para a legitimação das iniciativas de responsabilidade social e sustentabilidade destacadas no texto.

O que observamos é que, apesar do caráter informativo, muitos textos comunicacionais de organizações não apresentam as contradições e problematizações sociais envolvidas na temática. Avaliamos que os textos devem dar espaço para a reflexão do leitor acerca da iniciativa retratada - possibilitando que ele ressignifique o discurso de acordo com sua interpretação, se aproprie dos conhecimentos e até mesmo construa lugares em que pode se posicionar e falar como indivíduo, uma vez que os discursos e os sistemas de representação constroem os lugares a partir dos quais se dá o posicionamento e a fala dos indivíduos (Woodward, 2000).

Dessa forma, fica o entendimento de que, para que a responsabilidade social e a sustentabilidade sejam incorporadas à cultura da organização e tragam retorno efetivo e a longo prazo em termos de imagem empresarial, os discursos da comunicação organizacional referentes aos 
temas devem deixar brechas para que as disputas ideológicas que envolvem tais temática sejam reiteradas nos discursos.

\section{REFERÊNCIAS}

BENETTI, Marcia. Análise do discurso: estudo de vozes e sentidos. In: LAGO, Claudia; BENETTI, Marcia. Metodologia de pesquisa em jornalismo. Petrópolis (RJ): Vozes, 2008.

BENETTI, Marcia; HAGEN, Sean. Jornalismo e imagem de si: o discurso institucional das revistas semanais. In: ENCONTRO DA COMPÓS, 18, 2009, Belo Horizonte. Anais... Belo Horizonte: PUC-MG, 2009.

BORGER, Fernanda Gabriela. Responsabilidade social: efeitos da atuação social na dinâmica empresarial. 2001. Tese (Doutorado em Administração) - Faculdade de Economia, Administração e Contabilidade, Universidade de São Paulo, 2001.

BUENO, Wilson da Costa. Comunicação empresarial e responsabilidade social. 2006. Disponível em: <http://www.metodista.br/poscom/cientifico/ publicacoes/docentes/artigos/artigo-0050>. Acesso em: 17/11/2011.

CAPRA, Frtijof. As conexões ocultas: ciências para uma vida sustentável. São Paulo: Editora Cultrix, 2002.

FORMENTINI, Marcia. Responsabilidade social como estratégia competitiva na formação da imagem empresarial. 2005. Disponível em: <http://www.pucrs.br/famecos/geacor/texto13-03.html>. Acesso em: 19/11/2011.

GENRO FILHO, Adelmo. O segredo da pirâmide: para uma teoria marxista do jornalismo. Porto Alegre: Tchê, 1987.

MASERA, Diego. Rumo ao consumo sustentável na América Latina e no Caribe. Programa das Nações Unidas para o meio ambiente (PNUMA- UNEP). 2001. Disponível em: <http://www.pnuma.org/industria/documentos/ conslacp.pdf>. Acesso em 15 ago. 2009.

NEVES, Fábio Bruno. Responsabilidade social como fator de contribuição na formação da imagem empresarial, sob a ótica dos funcionários: um estudo na Cosern. 2008. Disponível em: <http://www.convibra. com.br/2008/artigos/368_0.pdf>. Acesso em: 16/11/2011.

OLIVEIRA, Ivone Lourdes de. Novo sentido da comunicação organizacional: construção de um espaço estratégico. In: CONGRESSO BRASILEIRO DE CIÊNCIAS DA COMUNICAÇÃO, XXVI, set. 2003, Belo Horizonte. Anais... São Paulo / Belo Horizonte: Intercom, 2003.

ORLANDI, Eni. Enfoque linguístico discursivo: o discurso da educação ambiental. In: TRAJBER, Rachel; MANZOCHI, Lucia H. (Orgs) Avaliando a educação ambiental no Brasil: materiais impressos. São Paulo: Gaia, 1996. 
Análise de discurso: princípios e procedimentos. Campinas (SP): Pontes, 2007.

PÊCHEUX, Michel. Análise automática do discurso. In: GADET, Françoise; HAK, Tony (Org). Por uma análise automática do discurso: uma introdução à obra de Michel Pêcheux. Campinas (SP): Editora da Unicamp, 1993.

PORTILHO, Fátima. Sustentabilidade ambiental, consumo e cidadania. São Paulo: Cortez, 2010.

REGINATO, Gisele Dotto. Em busca da complexa simplicidade: o consumo no discurso jornalístico da revista Vida Simples. Dissertação (mestrado). Universidade Federal de Santa Maria, Programa de Pós-Graduação em Comunicação, Santa Maria, 2011.

SANTA CRUZ, Lucia Maria Marcellino de. Responsabilidade social: visão e intermediação da mídia na redefinição do público e do privado. Dissertação (Mestrado em Comunicação e Cultura) - Universidade Federal do Rio de Janeiro, 2006.

SANTOS, Luciane Lucas dos. A comunicação subjacente à cultura do desperdício: o desenvolvimento sustentável como linha de fratura na produção capitalista. Revista Famecos, v. 1, n. 26, p. 102-110, abril 2005.

SARTOR, Basilio Alberto. Jornalismo e comunicação organizacional em diálogo: imagens-conceito da assessoria de imprensa e interações entre fontes, assessores e jornalismo. Dissertação (Mestrado em Comunicação) - Universidade Federal do Rio Grande do Sul, Programa de Pós-Graduação em Comunicação e Informação, Porto Alegre, 2011.

SOUZA, Marcos Gouvêa de. Metaconsumidor: a transformação do mercado pela percepção do consumidor global sobre sustentabilidade e consumo consciente. São Paulo: GS\&MD, 2010.

STORCH, Laura Strelow. O leitor imaginado no jornalismo de revista: uma proposta metodológica. Tese (Doutorado em Comunicação e Informação) - Universidade Federal do Rio Grande do Sul, Programa de Pós-Graduação em Comunicação e Informação, Porto Alegre, 2012.

VALE. Vale no mundo. 2011.34 p. Disponível em: <http://200.225.83.183/audiovideo/VALE\%20NO\%20MUNDO_A_1T11_ Port_OK.pdf>. Acesso em: 15/11/2011.

VALE. Relatório de sustentabilidade - 2010. 2011. 137 p. Disponível em: <http://200.225.83.183/_audiovideo/Relat\%C3\%B3rio\%20de\%20Sustentabilidade\%20Vale\%202010-\%20PDF.pdf>. Acesso em: 15/11/2011.

WOODWARD, Kathryn. Identidade e diferença: uma introdução teórica e conceitual. In: SILVA, Tomaz Tadeu da (Org). Identidade e diferença. Petrópolis (RJ): Vozes, 2000.

$* * *$

Recebido em: 03.09.2012 / Aceito em: 10.02.2013 